\title{
Effectiveness and reliability of traditional open surgery in atypical localizations of osteoid osteoma
}

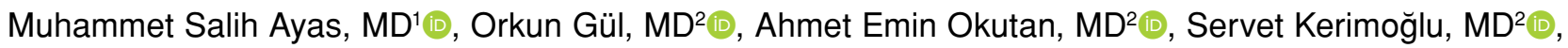

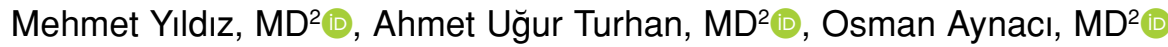 \\ 1Department of Orthopedics and Traumatology, Erzurum Regional Training and Research Hospital, Erzurum, Turkey \\ ${ }^{2}$ Department of Orthopedics and Traumatology, Karadeniz Technical University, Trabzon, Turkey
}

Osteoid osteoma (OO) is a benign, bone-forming tumor. The incidence is $2-3 \%$ of all primary bone neoplasms and $10-20 \%$ of benign bone tumors. ${ }^{[1]}$ Osteoid osteoma generally appears as a single, round lytic lesion (nidus) smaller than $2 \mathrm{~cm}$. It is surrounded by a sclerotic bone area in the metaphysis of a long bone ${ }^{[2]}$ Typically, radiography, computed tomography (CT), magnetic resonance imaging (MRI), and technetium-99m bone scans are used for imaging. Computed tomography is a very good imaging method for OO, clearly showing nidus and reactive bone sclerosis. ${ }^{[3] \mathrm{s}}$

Previous studies have reported OOs in many bones. Typical localizations of OOs are the long bones of the lower extremities (femur and tibia), which account for about $50-60 \%$ of cases. $^{[4,5]}$ Approximately $10 \%$ of $\mathrm{OO}$ cases are in the

Received: February 17, 2020

Accepted: March 28, 2020

Published online: June 30, 2020

Correspondence: Muhammet Salih Ayas, MD. Erzurum Bölge Eğitim ve Araştırma Hastanesi Ortopedi ve Travmatoloji Kliniği. 25240 Yakutiye, Erzurum, Türkiye.

E-mail: muhammetsalihayas@yahoo.com.tr

Doi: $10.5606 /$ ehc. 2020.74333

Citation: Ayas MS, Gül O, Okutan AE, Kerimoğlu S, Yıldız M, Turhan $\mathrm{AU}$, et al. Effectiveness and reliability of traditional open surgery in atypical localizations of osteoid osteoma. Jt Dis Relat Surg 2020:31(3):541-547.

\section{(02020 All right reserved by the Turkish Joint Diseases Foundation}

This is an open access article under the terms of the Creative Commons Attribution-NonCommercial License, which permits use, distribution and reproduction in any medium, provided the original work is properly cited and is not used for commercial purposes (http://creativecommons.org/licenses/by-nc/4.0/).

\section{ABSTRACT}

Objectives: This study aims to evaluate traditional open surgery results of osteoid osteomas (OOs) in atypical localizations and explore whether open surgery can be a safe alternative in localizations where radiofrequency ablation (RFA) may not be suitable.

Patients and methods: A total of 26 patients (20 males, 6 females; mean age $23.3 \pm 14.2$ years; range, 4 to 65 years) having OO in atypical localizations between January 2008 and January 2017 were retrospectively evaluated. All patients underwent traditional open surgery under anesthesia. All patients were followed-up, and their clinical success and complications were evaluated. The pain intensity was assessed using the visual analog scale (VAS).

Results: The postoperative first year VAS score was $0.2 \pm 0.5$ (range, $0-2) \quad(p<0.005)$. None of the patients showed any complications. No recurrences were reported at the end of the first year. All patients were relieved from pain due to $\mathrm{OO}$ in atypical localizations.

Conclusion: Although RFA has been accepted as the preferred treatment for $\mathrm{OO}$, traditional open surgery may still be used for $\mathrm{OO}$ in atypical localizations yielding perfect clinical results with fewer complications. It is a safe alternative for localizations such as carpal bones, distal ulna, hand and foot where RFA complications can be seen more frequently. In these localizations, traditional open surgery can be recommended as the first treatment choice.

Keywords: Atypical, open surgery, osteoid osteoma, radiofrequency ablation, traditional, visual analog scale.

vertebrae. ${ }^{[6-8]}$ Other localizations have been defined as atypical. ${ }^{[6,9]}$ However, still no consensus has been reached on this topic.

The most commonly used technique for the definitive treatment of $\mathrm{OO}$ lesions in recent years is percutaneous CT-guided radiofrequency ablation (RFA). ${ }^{[10,11]}$ However, percutaneous treatment has some limitations. The process lasts for four to six min, 
the temperature rises up to 90 degrees during this time, ${ }^{[12-14]}$ and hyperthermia in the surrounding tissues may occur. Therefore, percutaneous treatment should be avoided in lesions close to neurovascular structures, in localizations with low soft tissue support, and in regions close to the articular cartilage. ${ }^{[14,15]}$

In this study, we aimed to evaluate traditional open surgery results of OOs in atypical localizations and explore whether open surgery can be a safe alternative in localizations where RFA may not be suitable.

\section{PATIENTS AND METHODS}

In this study, 26 patients ( 20 males, 6 females; mean age $23.3 \pm 14.2$ years; range, 4 to 65 years) diagnosed with OO between January 2008 and January 2017 and treated with traditional open surgery at the Karadeniz Technical University Faculty of Medicine were retrospectively examined. Osteoid osteoma diagnosis was achieved with patient history and radiographic imaging $\mathrm{X}$-ray, $\mathrm{CT}$, MRI, and bone scintigraphy. Radiological imaging was carried out by an experienced radiologist at Karadeniz Technical University. The imaging results were analyzed, and an appropriate skin incision was planned. Osteoid osteomas in areas other than the femur and tibia are accepted as atypical. ${ }^{[4-9]}$ The study protocol was approved by the Karadeniz Technical University Faculty of Medicine Ethics Committee (Ref No: 2017-213). A written informed consent was obtained from each patient. The study was conducted in accordance with the principles of the Declaration of Helsinki. The study inclusion criteria were as follows: patients with a follow-up time of at least one year, patients treated with traditional open surgery, patients histopathologically diagnosed with OO, and patients who underwent surgery at the orthopedics clinic and had an atypical localization. The pathological analysis was carried out by an experienced pathologist working at Karadeniz Technical University. The exclusion criteria were as follows: patients who underwent surgery at another clinic, patients without a follow-up time of at least one year, and patients who missed the first-year check-up.

All patients were evaluated in terms of age, sex, pre- and postoperative visual analog scale (VAS) scores, bone localization, relationship to the joint, pathological results, nidus localization, and complications. Postoperative VAS was evaluated in the postoperative first year. All surgical treatments of the patients were carried out by a surgical team working in the same clinic. All surgeries were carried out using the traditional open surgery method. The patients were prepared with general or regional anesthesia. The anatomical localization of the lesions was determined with preoperative imaging techniques prior to the surgery. Intraoperative C-arm fluoroscopy was used. Cortical lesions were removed with the technique described by Campanacci ${ }^{[16]}$ and sent for a histopathological examination. For intramedullary, intraarticular, and juxtaarticular lesions, the region cortex determined by imaging techniques was reached by opening a window with the help of an osteotome, and the lesion was sent for a histopathological examination.

None of the patients used plaster or splint in the postoperative period. The joint movements following the excision of both upper and lower limb lesions started on the first postoperative day. All patients were mobilized within the first postoperative day. Patients who had undergone upper limb surgery were hospitalized for one day, and those who had undergone lower limb surgery were hospitalized for three days. For the lower extremity areas, partial weight was immediately allowed with crutches, and full weight was allowed at the end of the fourth week. The extremities of the patients treated in the femoral neck area were given a partial load for three weeks. The load was gradually increased to give full load in the sixth week.

All patients were clinically, radiologically, and histopathologically diagnosed with OO. Pain was significantly reduced postoperatively in all patients.

\section{Statistical analysis}

IBM SPSS version 22.0 was used (IBM Corp., Armonk, NY, USA) for the statistical analysis of research data. The categorical variables were presented as number and percentage, and the continuous variables were presented as mean \pm standard deviation and median (the smallest and the biggest values) in the descriptive statistics. The severity of pain was compared using VAS with the Wilcoxon test preoperatively and in the first postoperative year. A $p$ value of 0.05 was considered to indicate statistical significance.

\section{RESULTS}

The preoperative VAS score was $4.8 \pm 1.1$ (range, 3-7), while the postoperative first year VAS score was $0.2 \pm 0.5$ (range, $0-2)(\mathrm{p}<0.005)$ (Table I). Patients with VAS values " 1 " and " 2 " did not have complaints of 


\begin{tabular}{|c|c|c|c|c|}
\hline \multicolumn{5}{|c|}{$\begin{array}{l}\text { TABLE I } \\
\text { Patients' demographic characteristics and results }(n=26)\end{array}$} \\
\hline Variable & $\mathrm{n}$ & $\%$ & Mean \pm SD & Range \\
\hline Age (year) & & & $23.3 \pm 14.2$ & $4-65$ \\
\hline \multicolumn{5}{|l|}{ Sex } \\
\hline Female & 6 & & & \\
\hline Male & 20 & & & \\
\hline \multicolumn{5}{|l|}{ Visual analog scale } \\
\hline Preoperative & & & $4.8 \pm 1.1$ & $3-7$ \\
\hline Postoperative & & & $0.2 \pm 0.5$ & $0-2$ \\
\hline \multicolumn{5}{|c|}{ Relationship with the joint } \\
\hline Yes & 2 & & & \\
\hline No & 24 & & & \\
\hline Pathology & \multicolumn{4}{|c|}{$\begin{array}{l}\text { Osteoid osteoma } \\
\text { (central nidus, surrounding new bone formation) }\end{array}$} \\
\hline \multicolumn{5}{|l|}{ Nidus localization } \\
\hline Intracortical & 14 & & & \\
\hline Endosteal & 6 & & & \\
\hline Medullary & 6 & & & \\
\hline Subperiosteal & 0 & & & \\
\hline Complication & \multicolumn{4}{|c|}{ No } \\
\hline Clinical success & & 100 & & \\
\hline Technical success & & 100 & & \\
\hline
\end{tabular}

OO in atypical localizations. Therefore, it was not considered as a complication. This study concluded that patients had mild pain due to the surgical procedure.

The most common involvement rates were $40.7 \%$ $(n=37)$ for the femur and $30.7 \%(n=28)$ for the tibia. The total involvement rate of these two localizations was $71.4 \%(n=65)$. A total of $26(28.6 \%)$ atypical localizations were assessed, including two in the radius $(2.2 \%)$ (one-third proximal, one-third distal), two in the ulna (2.2\%) (one-third distal), three in the phalanges of hand (3.3\%) (two-fifth finger proximal and one-fourth finger distal), one in the metacarpal bone (1.1\%) (second metacarpal), one in the scaphoid (1.1\%), five in the fibula (5.5\%) (one one-third proximal and four one-third distal), four in the phalanges of foot $(4.4 \%)$ (first finger distal, second middle, second distal, and third proximal), one in the metatarsal bone (1.1\%) (third metatarsal), one in the cuboid $(1.1 \%)$, two in the calcaneus $(2.2 \%)$, one in the lateral cuneiform (1.1\%), one in the iliac $(1.1 \%)$, one in the pubis $(1.1 \%)$, and one in the vertebrae (1.1\%) (Table II).

Surgical complications, such as injury, infection, or wounds, in neurovascular structures did not occur in any of the patients (Table III).
The localization of atypical OOs in the nidus was as follows: 14 intracortical, six endosteal, and six medullary. Subperiosteal localization was not

\begin{tabular}{|lcc|}
\multicolumn{4}{c}{ TABLE II } \\
Distribution of typical - atypical localizations determined in \\
the study according to the bones & $(\mathrm{n}=91)$ \\
\hline Characteristic & $\mathrm{n}$ & $\%$ \\
\hline Typical localization & 65 & 71,4 \\
Femur & 37 & 40.7 \\
Tibia & 28 & 30.7 \\
Atypical localization & 26 & 28.6 \\
Radius & 2 & 2.2 \\
Ulna & 2 & 2.2 \\
Metacarpal bone & 1 & 1.1 \\
Scaphoid & 1 & 1.1 \\
Phalanges of hand & 3 & 3.3 \\
Fibula & 5 & 5.5 \\
Calcaneus & 2 & 2.2 \\
Cuboid & 1 & 1.1 \\
Lateral cuneiform & 1 & 1.1 \\
Metatarsal bone & 1 & 1.1 \\
Phalanges of foot & 4 & 4.4 \\
Iliac & 1 & 1.1 \\
Pubis & 1 & 1.1 \\
Vertebrae & 1 & 1.1 \\
\hline
\end{tabular}


detected in patients with atypical localization (Figure 1).

\section{DISCUSSION}

The present study demonstrated that traditional open surgery is safe in 26 patients with OOs in atypical localizations, and there was no complication.

Radiofrequency ablation yields perfect results in several localizations. However, RFA is not suitable for regions with low soft tissue support and those near neurovascular structures. The present study suggested that traditional open surgery was a safe alternative for regions in which RFA complications are more and where RFA treatment is not possible, such as carpal bones, distal ulna, hand, and foot. ${ }^{[17]}$

The first major series on the localization of atypical $\mathrm{OO}$ was carried out by Akhlaghpour et al. ${ }^{[6]}$ using RFA. Twenty-one atypical localizations were defined in this series. In the present study, 26 atypical localizations were determined. In the study by Akhlaghpour et al., ${ }^{[6]}$ the talus localizations were the most common of atypical localizations

\begin{tabular}{|c|c|c|c|c|c|}
\hline \multicolumn{6}{|c|}{$\begin{array}{l}\text { TABLE III } \\
\text { Summary of demographic and clinical characteristics of atypical localizations }\end{array}$} \\
\hline Patient & Age/Sex & Bone localization & $\begin{array}{l}\text { Relationship with } \\
\text { the joint }\end{array}$ & $\begin{array}{c}\text { VAS } \\
\text { Preop/Postop }\end{array}$ & $\begin{array}{c}\text { Nidus } \\
\text { localization }\end{array}$ \\
\hline \multicolumn{6}{|l|}{ Upper extremity } \\
\hline 1 & $34 / \mathrm{M}$ & Ulna one-third distal & No & $5 / 0$ & Intracortical \\
\hline 2 & $56 / M$ & Ulna one-third distal & + & $4 / 0$ & Intracortical \\
\hline 3 & $4 / M$ & Radius one-third distal & No & $4 / 0$ & Intracortical \\
\hline 4 & $65 / M$ & Radius one-third proximal & No & $4 / 0$ & Endosteal \\
\hline 5 & $47 / M$ & Scaphoid & + & $4 / 0$ & Intracortical \\
\hline 6 & $39 / F$ & $2^{\text {th }}$ metacarpal & No & $4 / 2$ & Endosteal \\
\hline 7 & $18 / \mathrm{F}$ & $5^{\text {th }}$ finger proximal phalan $x$ & No & $4 / 0$ & Medullary \\
\hline 8 & $24 / F$ & $4^{\text {th }}$ finger distal phalan $x$ & No & $4 / 0$ & Endosteal \\
\hline 9 & $18 / \mathrm{F}$ & $5^{\text {th }}$ finger proximal phalanx & No & $5 / 0$ & Medullary \\
\hline Lower extremity & $19 / M$ & & & & \\
\hline 10 & $13 / M$ & Fibula one-third proximal & No & $4 / 1$ & Intracortical \\
\hline 11 & $13 / M$ & Fibula one-third distal & No & $3 / 0$ & Intracortical \\
\hline 12 & $15 / M$ & Fibula one-third distal & No & $7 / 0$ & Intracortical \\
\hline 13 & $16 / M$ & Fibula one-third distal & No & $4 / 0$ & Intracortical \\
\hline 14 & $12 / M$ & Fibula one-third distal & No & $7 / 0$ & Intracortical \\
\hline 15 & $14 / \mathrm{M}$ & Calcaneus & No & $6 / 0$ & Medullary \\
\hline 16 & $27 / F$ & Calcaneus & No & $3 / 1$ & Endosteal \\
\hline 17 & $25 / M$ & Cuboid & No & $4 / 0$ & Medullary \\
\hline 18 & $17 / \mathrm{M}$ & Lateral cuneiform & No & $5 / 0$ & Endosteal \\
\hline 19 & $24 / M$ & $2^{\text {th }}$ finger middle phalan $x$ & No & $5 / 0$ & Intracortical \\
\hline 20 & 20/M & $3^{\text {rd }}$ finger proximal phalanx & No & $7 / 0$ & Intracortical \\
\hline 21 & 19/M & $1^{\text {st }}$ finger distal phalan $\mathrm{x}$ & No & $5 / 0$ & Endosteal \\
\hline 22 & $13 / F$ & $2^{\text {th }}$ finger distal phalanx & No & $4 / 0$ & Medullary \\
\hline 23 & & $3^{\text {rd }}$ metatarsal & No & $6 / 1$ & Intracortical \\
\hline \multicolumn{6}{|l|}{ Pelvis } \\
\hline 24 & $20 / M$ & Ileum & No & $5 / 0$ & Intracortical \\
\hline 25 & $12 / M$ & Pubis & No & $6 / 0$ & Intracortical \\
\hline \multicolumn{6}{|l|}{ Vertebra } \\
\hline 26 & 23/M & L3 & No & $5 / 1$ & Medullary \\
\hline
\end{tabular}



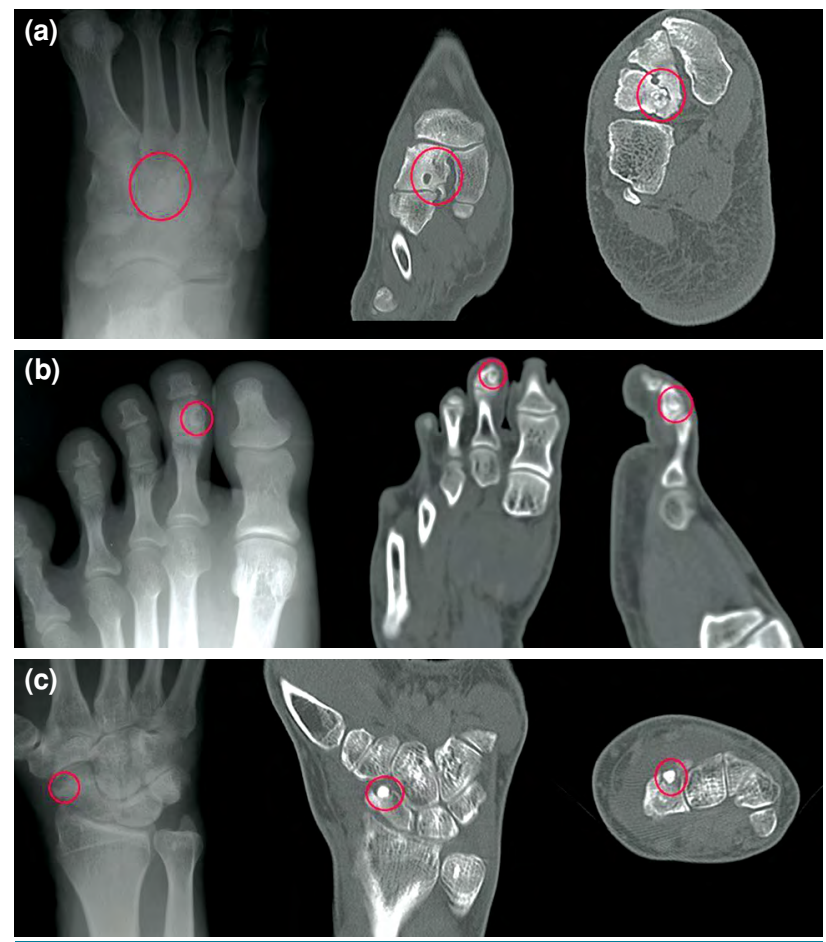

FIGURE 1. Images showing nidus of atypical osteoid osteoma lesions in various locations. (a) Patient no. 18: 25 years old, male, X-ray and computed tomography (CT) image, lateral cuneiform, endosteal nidus. (b) Patient no. 19: 17 years old, male, X-ray and CT image, second finger middle phalanx, intracortical nidus. (c) Patient no. 5: 47 years old, male, X-ray and CT image, scaphoid, intracortical nidus. with eight cases (6\%). No talus localization was determined in the present study. The most common atypical localization was the fibula with five cases (5.5\%). The atypical localization distribution in the present study was more balanced.

Successful results were reported on different atypical localizations with the traditional open surgery. No early or late complications were noted. Hamdi et al. ${ }^{[15]}$ applied traditional open surgery to 17 patients with OO, all with atypical localization. They reported perfect results in all patients and no recurrences or complications. As a result, they concluded that open surgery was the most suitable approach in the treatment of $\mathrm{OO}$.

The surgical treatment of $\mathrm{OO}$ is the removal of the nidus. ${ }^{[18]}$ The traditional treatment is the removal of the nidus by en bloc resection or curettage. ${ }^{[1]}$ In addition, CT-guided percutaneous RFA has become the primary treatment option since the 1990s. ${ }^{[7,11,19]}$ The percutaneous treatment has some advantages, including minimal surgical scars, short operation time, fast healing, short hospitalization, and reduced costs. ${ }^{[7,19]}$ However, the percutaneous treatment also has its limitations. It should be avoided in small bones, in areas with low soft tissue support, and in localizations close to neurovascular structures or articular cartilage..$^{[14,15,20]}$ Rachbauer et al. ${ }^{[21]}$ showed that RFA

\section{TABLE IV}

Results of osteoid osteoma case series with traditional open surgical treatment

\begin{tabular}{|c|c|c|c|c|c|}
\hline Study & Surgical procedure & $\mathrm{n}$ & Localization & Success rate (\%) & Complication \\
\hline Ward et al. ${ }^{[3]}$ & $\begin{array}{l}\text { TOS (curettage/ } \\
\text { en bloc resection) }\end{array}$ & $15 / 4$ & Mixed & 100 & No \\
\hline Rosenthal et al. ${ }^{[27]}$ & TOS/RFA & $68 / 33$ & Mixed & $91 / 88$ & $\begin{array}{l}\text { Six unsuccessful treatments, } \\
\text { one PCL rupture, and one sciatic } \\
\text { nerve injury }\end{array}$ \\
\hline Campanacci et al. ${ }^{[16]}$ & $\begin{array}{l}\text { TOS (curettage/ } \\
\text { en bloc resection) }\end{array}$ & $89 / 8$ & Mixed & 100 & No \\
\hline Yildiz et al. ${ }^{[29]}$ & TOS & 110 & Mixed & 95 & No \\
\hline Sluga et al. ${ }^{[28]}$ & $\begin{array}{l}\text { TOS (curettage/ } \\
\text { en bloc resection) }\end{array}$ & $81 / 25$ & Limbs & $85 / 86.5$ & $\begin{array}{l}\text { Eight unsuccessful treatments, } \\
\text { two tibial fractures/ } \\
\text { one unsuccessful treatment, } \\
\text { one infection, and one fracture } \\
\text { (undefined) }\end{array}$ \\
\hline Yang et al. ${ }^{[26]}$ & TOS & 20 & Mixed & Undefined & Three unsuccessful treatments \\
\hline Hamdi et al. ${ }^{[15]}$ & TOS & 17 & Atypical-hand & 100 & No \\
\hline Present study & TOS & 26 & Atypical-mixed & 100 & No \\
\hline
\end{tabular}


applied for six min to cattle cadavers was effective in an area of $1 \mathrm{~cm}$ in the cortical bone and $3 \mathrm{~cm}$ in the spongious bone, and that the temperature of the surrounding tissues increased up to 50 degrees. Hence, it was suggested that the complication risk of RFA application might increase in areas with atypical localizations.

Many studies reported skin burn, necrosis, and numbness as the complications of RFA, which is the most popular current treatment option. Although these complications are rare in major series, they are important for patients. Rimondi et al. ${ }^{[22]}$ reported skin burn as a complication in a patient with proximal tibial metaphyseal localization. Similarly, Vanderschueren et al. ${ }^{[23]}$ reported skin and fat necrosis in a patient with tibial localization after RFA. Lindner et al. ${ }^{[2]}$ reported skin burns in a patient with tibial localization after RFA. In a study on atypical localizations, Akhlaghpour et al. ${ }^{[6]}$ reported skin burns in a patient with phalanx localization. Oç et al. ${ }^{[25]}$ reported that two of 87 patients exhibited second-degree skin burns in the anterior part of the tibia and one patient with metacarpal localization experienced numbness. Based on these data, traditional open surgery may be recommended as the primary treatment, particularly in localizations having insufficient soft tissue support, localizations close to neurovascular structures, and some atypical localizations.

The treatment of OO with traditional open surgery has been evaluated by many studies. Some studies reported unsuccessful results for up to $30 \%$ and criticized open surgery due to the long hospitalization duration..$^{[17,18,26]}$ Rosenthal et al. ${ }^{[27]}$ compared traditional open surgery with RFA and reported recurrence in six patients, posterior cruciate ligament damage in one patient, and sciatic nerve damage in one patient as complications in the open surgery group. Sluga et al. ${ }^{[28]}$ reported recurrence in nine of 106 patients undergoing traditional open surgery, fractures in three patients, and an infection in one patient. In contrast, some studies reported no recurrences and complications after traditional open surgery. Ward et al. ${ }^{[3]}$ reported perfect results in their study carried out with 19 patients treated with traditional open surgery. They did not report any complications. Campanacci et al. ${ }^{[16]}$ reported $100 \%$ success and did not report any complications in their study on 97 patients treated with traditional open surgery.

Furthermore, Yildiz et al. ${ }^{[2]}$ reported no complications in their study carried out with 110 patients treated with traditional open surgery. Also, in the present study, no recurrence or complications were noted in any of the regions (Table IV). The data showed that low complication ratios, low recurrence ratios, reasonable hospitalization durations, and high clinical success were possible with traditional open surgery in atypical regions. Therefore, careful planning was the most important step.

The first limitation of this study was that all patients were treated with traditional open surgery. Second, the study was carried out retrospectively. Third, the study included no RFA comparison group. Fourth, the patients' data were evaluated at the end of the first year. The patients might have had a recurrence and applied to another clinic. Comparative studies with prospective, larger patient groups are needed to draw a better conclusion.

In conclusion, although percutaneous RFA is the preferential treatment method in typical OO localizations, perfect clinical results can be achieved with traditional open surgery in aty pical localizations. Therefore, this study shows that traditional open surgery may be a safe alternative for regions in which RFA complications are more and where RFA treatment is not possible. In these localizations, traditional open surgery can be recommended as the first treatment choice.

\section{Declaration of conflicting interests}

The authors declared no conflicts of interest with respect to the authorship and/or publication of this article.

\section{Funding}

The authors received no financial support for the research and/or authorship of this article.

\section{REFERENCES}

1. Ciftdemir M, Tuncel SA, Usta U. Atypical osteoid osteomas. Eur J Orthop Surg Traumatol 2015;25:17-27.

2. Atesok KI, Alman BA, Schemitsch EH, Peyser A, Mankin H. Osteoid osteoma and osteoblastoma. J Am Acad Orthop Surg 2011;19:678-89.

3. Ward WG, Eckardt JJ, Shayestehfar S, Mirra J, Grogan $\mathrm{T}$, Oppenheim W. Osteoid osteoma diagnosis and management with low morbidity. Clin Orthop Relat Res 1993;291:229-35.

4. Barei DP, Moreau G, Scarborough MT, Neel MD. Percutaneous radiofrequency ablation of osteoid osteoma. Clin Orthop Relat Res 2000;373:115-24.

5. Sproule JA, Khan F, Fogarty EE. Osteoid osteoma: painful enlargement of the second toe. Arch Orthop Trauma Surg 2004;124:354-6.

6. Akhlaghpoor S, Aziz Ahari A, Arjmand Shabestari A, Alinaghizadeh MR. Radiofrequency ablation of osteoid osteoma in atypical locations: a case series. Clin Orthop Relat Res 2010;468:1963-70.

7. Hoffmann RT, Jakobs TF, Kubisch CH, Trumm CG, Weber C, Duerr HR, et al. Radiofrequency ablation in 
the treatment of osteoid osteoma-5-year experience. Eur J Radiol 2010;73:374-9.

8. Pinto $\mathrm{CH}$, Taminiau AH, Vanderschueren GM, Hogendoorn PC, Bloem JL, Obermann WR. Technical considerations in CT-guided radiofrequency thermal ablation of osteoid osteoma: tricks of the trade. AJR Am J Roentgenol 2002;179:1633-42.

9. Chai JW, Hong SH, Choi JY, Koh YH, Lee JW, Choi JA, et al. Radiologic diagnosis of osteoid osteoma: from simple to challenging findings. Radiographics 2010;30:737-49.

10. Tanrıverdi B, Erbahçeci Salık A, Çetingök H, Edipoğlu E, Bilgili MG, Güven K, et al. Multidisciplinary approach in the treatment of osteoid osteoma with radiofrequency ablation. Jt Dis Relat Surg 2020;31:255-9.

11. Earhart J, Wellman D, Donaldson J, Chesterton J, King E, Janicki JA. Radiofrequency ablation in the treatment of osteoid osteoma: results and complications. Pediatr Radiol 2013;43:814-9.

12. Papathanassiou ZG, Petsas T, Papachristou D, Megas P. Radiofrequency ablation of osteoid osteomas: five years experience. Acta Orthop Belg 2011;77:827-33.

13. Ward E, Munk PL, Rashid F, Torreggiani WC. Musculoskeletal interventional radiology: radiofrequency ablation. Radiol Clin North Am 2008;46:599-610.

14. Rybak LD. Fire and ice: thermal ablation of musculoskeletal tumors. Radiol Clin North Am 2009;47:455-69.

15. Hamdi MF, Tarhouni L, Daghfous M, Bergaoui N, Baccari S. Osteoid osteoma of the phalanx and metacarpal bone: report of 17 cases. Musculoskelet Surg 2015;99:61-5.

16. Campanacci M, Ruggieri P, Gasbarrini A, Ferraro A, Campanacci L. Osteoid osteoma. Direct visual identification and intralesional excision of the nidus with minimal removal of bone. J Bone Joint Surg [Br] 1999;81:814-20.

17. Atik OŞ. Is there something new and interesting in my article? Eklem Hastalik Cerrahisi 2019;30:69.

18. Bilgin SS, Yildiz Y, Güçlü B, Sağlik Y. Osteoid osteoma in the hand: an evaluation of eight patients. Acta Orthop Traumatol Turc 2004;38:206-11.
19. Abboud S, Kosmas C, Novak R, Robbin M. Long-term clinical outcomes of dual-cycle radiofrequency ablation technique for treatment of osteoid osteoma. Skeletal Radiol 2016;45:599-606.

20. Rosenthal DI, Hornicek FJ, Torriani M, Gebhardt MC, Mankin HJ. Osteoid osteoma: percutaneous treatment with radiofrequency energy. Radiology 2003;229:171-5.

21. Rachbauer F, Mangat J, Bodner G, Eichberger P, Krismer M. Heat distribution and heat transport in bone during radiofrequency catheter ablation. Arch Orthop Trauma Surg 2003;123:86-90.

22. Rimondi E, Mavrogenis AF, Rossi G, Ciminari R, Malaguti C, Tranfaglia C, et al. Radiofrequency ablation for nonspinal osteoid osteomas in 557 patients. Eur Radiol 2012;22:181-8.

23. Vanderschueren GM, Taminiau AH, Obermann WR, Bloem JL. Osteoid osteoma: clinical results with thermocoagulation. Radiology 2002;224:82-6.

24. Lindner NJ, Ozaki T, Roedl R, Gosheger G, Winkelmann W, Wörtler K. Percutaneous radiofrequency ablation in osteoid osteoma. J Bone Joint Surg [Br] 2001;83:391-6.

25. Oc Y, Kilinc BE, Cennet S, Boyacioglu MM, Ertugrul R, Varol A. Complications of computer tomography assisted radiofrequency ablation in the treatment of osteoid osteoma. Biomed Res Int 2019;2019:4376851.

26. Yang WT, Chen WM, Wang NH, Chen TH. Surgical treatment for osteoid osteoma --- experience in both conventional open excision and CT-guided mini-incision surgery. J Chin Med Assoc 2007;70:545-50.

27. Rosenthal DI, Hornicek FJ, Wolfe MW, Jennings LC, Gebhardt MC, Mankin HJ. Percutaneous radiofrequency coagulation of osteoid osteoma compared with operative treatment. J Bone Joint Surg [Am] 1998;80:815-21.

28. Sluga M, Windhager R, Pfeiffer M, Dominkus M, Kotz R. Peripheral osteoid osteoma. Is there still a place for traditional surgery? J Bone Joint Surg [Br] 2002;84:249-51.

29. Yildiz Y, Bayrakci K, Altay M, Saglik Y. Osteoid osteoma: the results of surgical treatment. Int Orthop 2001;25:119-22. 